\title{
Screening for anxiety disorders in children
}

\author{
Ellin Simon · Susan Maria Bögels
}

Received: 25 August 2008/Accepted: 8 April 2009/Published online: 5 May 2009

(C) The Author(s) 2009. This article is published with open access at Springerlink.com

\begin{abstract}
Anxiety disorders are highly prevalent and have negative consequences on individual and societal level. This study examined the usefulness of screening for anxiety disorders in primary school children. More specifically, the value of the screening method to discriminate between and to predict anxiety disorders was studied. Children and their parents were selected if the children had self-reported scores on the screening questionnaire Screen for Child Anxiety Related Emotional Disorders-71 (SCARED-71) within the top-15\% (High-anxious) or from two points below to two points above the median (Mediananxious). Of the selected children, 183 high-anxious children and their parents, and 80 median-anxious children and their parents took part in a diagnostic interview, the Anxiety Disorder Interview Schedule (ADIS). Of the highanxious children, $60 \%$ had an anxiety disorder versus $23 \%$ of the median-anxious children, whereas groups did not differ on rates of dysthymia/depression and attention deficit hyperactivity disorder. The diagnoses separation anxiety disorder, social phobia and specific phobia were specifically predicted by the corresponding subscales of the screening questionnaire, while the diagnosis generalised anxiety disorder was not predicted by any of the subscales. The screening method has proven its utility for discriminating between children with and without anxiety disorders when applying the top-15\% cut-off. Moreover, separation
\end{abstract}

E. Simon $(\bowtie)$

Maastricht University, Universiteitssingel 40,

6200 MD Maastricht, The Netherlands

e-mail: e.simon@dmkep.unimaas.nl

S. M. Bögels

University of Amsterdam, Nieuwe Prinsengracht 130,

1018 VZ Amsterdam, The Netherlands

e-mail: s.m.bogels@uva.nl anxiety disorder, social phobia, and specific phobia, all known to be prevalent and debilitating childhood anxiety disorders, can be predicted by the corresponding subscale of the screening instrument.

Keywords Anxiety disorders - Screening · Prevalence . SCARED-71 · ADIS

\section{Introduction}

Anxiety disorders have detrimental effects on an individual's quality of life and functioning. For children, this entails difficulties at school and in social interactions [18, $21,52,53]$. Additionally, anxiety disorders are comorbid with other anxiety or affective disorders [2, 31, 33] and can lead to depression $[3,9,44,51]$, other mental disorders such as substance use disorder [56] and more severe anxiety disorders $[32,43]$. Furthermore, the decrease in quality of life and functioning, together with the need for treatment, place a burden on society via indirect and direct costs. For example, in 2003, anxiety disorders accounted for $0.5 \%$ of the total health care costs in The Netherlands, and costs were estimated at 275.2 million euro's [49]. Moreover, a recent cost-of-illness study [7] revealed that families with clinically anxious children reached societal costs that were more than 20 times higher than families from the general population.

Estimations of lifetime prevalence of anxiety disorders in childhood and adolescence range between 8 and 27\% [13], and Costello and colleagues reported that the lifetime prevalence of anxiety disorders is already $9.9 \%$ at age 16 [14]. In adulthood, anxiety disorders are the most common psychiatric disorders, with a $29 \%$ lifetime prevalence [29]. In another study, $80.5 \%$ of 21 years of age with a diagnosis 
of anxiety had received an anxiety diagnosis before they reached the age of 18 [41]. The majority of anxiety disorders thus have their onset in childhood and adolescence. Early onset anxiety disorders ( $<13$ years of age) have a tendency to follow a chronic course [12, 22, 28]. Even though effective treatment of anxiety disorders exists [42], only $40 \%$ of individuals hindered by an anxiety disorder initiates help seeking within a year. Christiana and colleagues reported that $60 \%$ of all individuals with an anxiety disorder seek help with a mean delay of 8 years. In fact, help-seeking behaviour was found to be inversely associated to time since onset and age at onset [11]. Moreover, early onset anxiety disorders have been found to have a more disabling and severe character $[23,26,30]$.

The negative consequences of anxiety disorders on a personal and societal level, together with the fact that enduring and early onset anxiety disorders lead individuals to initiate treatment less, add up for the need to detect children with anxiety (disorders) in an early stage. A screening tool generally provides insight in the anxiety level within a matter of minutes and laypersons can administer it [20]. Therefore, screening tools, such as questionnaires, enable to measure anxiety symptoms in a time- and cost-effective manner. This creates the opportunity to identify high-anxious children, to inform children and parents about anxiety and its consequences, to prevent anxiety disorders, and to intervene closer to onset. Additionally, utilising a screening tool possibly decreases the child's dependence on parents or teachers to play an active part in or be aware of possible anxiety problems. Due to the fact that children do not readily disclose anxious feelings and that anxiety symptoms are usually not easy to observe for the environment, dysfunctional child anxiety remains relatively unnoticed by caretakers.

The Screen for Anxiety Related Emotional Disorders (SCARED) [5], Dutch translation and revision by Muris and colleagues (SCARED-R) [37], is a questionnaire suitable for screening childhood anxiety disorders, also in community populations. Its subscales are linked to the categories of the Diagnostic and Statistical Manual of Mental Disorders [1]: separation anxiety disorder, generalised anxiety disorder, social phobia, panic disorder, obsessive-compulsive disorder, specific phobia, and posttraumatic stress disorder. The SCARED-R possesses good internal consistencies of the total and subscales scores [34, 38, 40], satisfactory test-retest reliability [38], and discriminates well between anxiety problems and other behaviour problems [34, 40]. Additionally, it correlates well with other measures of anxiety, like the Spence Children's Anxiety Scale [39, 50], and is sensitive for treatment effects [35]. The current study uses the 71-item SCARED (SCARED-71) [6]. The SCARED-71 adds 5 extra items to the social phobia subscale, which was composed of 4 items in the subscale of the SCARED-R. The 4 original social phobia items all address fear of interaction with unfamiliar people, whereas the 5 added items refer to other important aspects of social phobia: fear of interaction with familiar people, fear of being evaluated, and psycho-physiological aspects of social phobia [8]. Two studies examined the predictive/discriminative value of the subscales of the SCARED-R, both yielding promising results. The first study was performed with a sample of elementary school children $(n=82)$ and used the child edition of the Structured Clinical Interview for DSM as diagnostic standard (KSCID) [24]. It appeared that the diagnoses separation anxiety disorder and generalised anxiety disorder were specifically predicted by their matching subscales of the SCARED-R [36]. The second study used a sample of clinically referred children/adolescents $(n=233)$ and also used the KSCID as diagnostic standard. It was shown that the SCARED-R subscales separation anxiety disorder, obsessive-compulsive disorder, post-traumatic stress disorder, panic disorder and social phobia predicted their corresponding diagnoses on the KSCID [34].

This study aims to investigate the usefulness of screening for anxiety disorders by children's self-report of anxiety symptoms on a questionnaire (SCARED-71) in primary school settings. It does so by comparing SCARED-71 scores to a diagnostic standard, the Anxiety Disorder Interview Schedule [47] in a large sample of children $(N=263)$. Moreover, the discriminative value of the subscales of the SCARED-71 is examined. To our knowledge, only one comparable study has been performed that also used a sample of primary school children [36]. Whereas that study relied only on the child interview, the current study includes both child and parent as informants in the interview. It was expected that (I) children selected as 'high-anxious' (SCARED-71 scores in the top-15\%) display significantly more anxiety diagnoses on the ADIS than children selected as median-anxious; (II) the subscales of the screening questionnaire predict the diagnoses on their corresponding category in the diagnostic interview.

\section{Method}

\section{Participants}

The participants were recruited for a longitudinal still ongoing study, approved by a Medical Ethical Committee, on the prevention of anxiety disorders. Children aged 8-13 were recruited via primary schools in rural and urban schools in the Southern part of the Netherlands. Of all approached children and parents, $52 \%(N=2,494)$ signed informed consent and these children completed the anxiety 
Table 1 Family demographic features of participants of high-anxious and median-anxious children

\begin{tabular}{|c|c|c|}
\hline & $\begin{array}{l}\text { High-anxious } \\
(n=188)\end{array}$ & $\begin{array}{l}\text { Median-anxious } \\
(n=82)\end{array}$ \\
\hline Boys $(n, \%)$ & $84(45 \%)$ & $44(54 \%)$ \\
\hline Age child (Mean, SD) & $9.92(1.23)$ & $10.22(1.13)$ \\
\hline $\begin{array}{l}\text { Professional help for mental } \\
\text { health children }(n, \%)^{\mathrm{a}}\end{array}$ & $19(10 \%)$ & $4(5 \%)$ \\
\hline $\begin{array}{l}\text { Children in family } \\
\text { (Mean, SD) }\end{array}$ & $2.27(0.94)$ & $2.15(0.79)$ \\
\hline Children first-born $(n, \%)$ & $103(55 \%)$ & $50(61 \%)$ \\
\hline $\begin{array}{l}\text { Parents divorced/living } \\
\text { apart }(n, \%)\end{array}$ & $39(21 \%)$ & $7(9 \%)^{* *}$ \\
\hline Biological father $(n, \%)$ & $174(93 \%)$ & $81(100 \%)^{*}$ \\
\hline Biological mother $(n, \%)$ & $187(100 \%)$ & $81(99 \%)$ \\
\hline \multicolumn{3}{|l|}{ Caucasian } \\
\hline Father $(n, \%)$ & $181(96 \%)$ & $79(96 \%)$ \\
\hline Mother $(n, \%)$ & $181(96 \%)$ & $78(95 \%)$ \\
\hline \multicolumn{3}{|l|}{ Parental age } \\
\hline Father (Mean, SD) & $41.84(4.43)$ & $42.39(3.92)$ \\
\hline Mother (Mean, SD) & $39.59(5.00)$ & $40.11(4.29)$ \\
\hline \multicolumn{3}{|l|}{ Parental educational level ${ }^{\mathrm{b}}$} \\
\hline Father (Mean, SD) & $5.11(1.96)$ & $5.29(2.10)$ \\
\hline Mother (Mean, SD) & $4.94(1.98)$ & $5.06(2.00)$ \\
\hline \multicolumn{3}{|l|}{ Current unemployment } \\
\hline Father $(n, \%)$ & $12(6 \%)$ & $4(5 \%)$ \\
\hline Mother $(n, \%)$ & $59(31 \%)$ & $27(33 \%)$ \\
\hline
\end{tabular}

questionnaire that was used as a screening tool (SCARED71). The participants eligible for the longitudinal study scored either in the top-15\% $(n=412$, referred to as highanxious) or from two points below to two points above the median ( $n=172$, referred to as median-anxious) on the SCARED-71. In order to achieve a balance in the number of boys and girls in the median and top- $15 \%$, separate top$15 \%$ and median cut-offs for boys and girls were calculated. Girls tend to score more anxiety symptoms than boys $[10,16]$. Participants were excluded from further participation if the children were found to show obvious developmental deviation, as based on clinical observation $(n=1)$.

Of the children labelled as high-anxious children, 188 (46\%) children and parents participated in the diagnostic interview. Of the children labelled as median-anxious, 82 (48\%) children and parents participated in the diagnostic interview. Demographic features of the high- and mediananxious children are depicted in Table 1. In the high-anxious and median- anxious group, there were 3 and 2 sibling dyads, respectively.

As can be seen in Table 1, parents of high-anxious children are significantly more often divorced or living apart than parents of median-anxious children. No significant differences were found with respect to all other demographic variables. Among others, the parents of highanxious and median-anxious children did not differ with respect to seeking professional help for their child's mental health.

\section{Anxiety screening}

The Screen for Child Anxiety Related Emotional Disorders (SCARED) was originally developed by Birmaher and colleagues $[4,5]$ and has been modified and revised over the years [e.g. 37]. In this study, the selection of the children was based on the child version of the 71-item Dutch version of the screening questionnaire, the SCARED-71. The choice for only using the child version came forth from pragmatic reasons (classical employment is more timeefficient). Moreover, as children with anxiety disorders are often not referred for treatment because the environment is not sufficiently aware of the severity of the anxiety symptoms [27], it seems important to detect children with severe anxiety and anxiety disorders on the basis of their own report. Furthermore, in the study of Wren and colleagues [57], it appeared that the child version yielded more information (on symptoms of separation anxiety disorder and panic disorder) than the parent version.

The SCARED-71 assesses a range of DSM-IV based anxiety symptomatology. More specifically, it taps symptoms of panic disorder (13 items), generalised anxiety disorder ( 9 items), social phobia ( 9 items), separation anxiety disorder (12 items), obsessive-compulsive disorder (9 items), post-traumatic stress disorder (4 items), and specific phobia (15 items). The SCARED-71 consists of 71 items rated on a three-point scale $(0=$ almost never, $1=$ sometimes, $2=$ often). The minimum score that could be obtained is 0 and the maximum score that could be obtained is 142 . The current study indexed girls with a cutoff above 60 , and boys with a cut-off above 46 as "highanxious" (top-15\%) for developing anxiety disorders. Girls with scores 2 points below/above the median of 30, and boys with 2 points below/above the median of 23 were labelled median-anxious. For this study, the homogeneity of the child-report of the 71 item SCARED-71 was high, $\alpha=0.94$, for the total score, and satisfactory for the social phobia scale, $\alpha=0.73$. The homogeneity of the subscale social phobia could not be ameliorated by deleting items, pointing to a unique contribution of every item within the scale. The homogeneities of the other subscales were as 
follows: panic disorder: $\alpha=0.86$, generalised anxiety disorder $\alpha=0.82$, separation anxiety disorder $\alpha=0.76$, obsessive-compulsive disorder: $\alpha=0.58$, post-traumatic stress disorder: $\alpha=0.79$, specific phobia: $\alpha=0.76$.

\section{Anxiety diagnoses}

The Anxiety Disorder Interview Schedule (ADIS) is a wellvalidated semi-structured diagnostic interview, suitable for measuring all anxiety disorders as listed in the DSM-IV as well as mood disorders and attention deficit hyperactivity disorder, in children from 7-17 years of age. This study utilised the child and parent version of the Dutch version of the ADIS [47] and was used to measure the presence of anxiety disorders, mood disorders and attention deficit hyperactivity disorder in the past year. Both the parent and child version of the ADIS possess good inter-rater and high test-retest reliability [48]. For the current study, more than $10 \%(n=29)$ of the interviews were videotaped and rerated by two trained research assistants. Regarding the presence of an anxiety disorder (any anxiety disorder present/no anxiety disorder present), the research assistants reached perfect agreement on the child interview, kappa $=1.00, p<0.01$, and substantial agreement on the parent interview, kappa $=0.73, p<0.01$. With respect to the number of diagnoses, the research assistants reached almost perfect agreement on both the child, $r=0.84$, $p<0.01$, and the parent interview, $r=0.95, p<0.01$. Finally, the research assistants reached almost perfect agreement regarding the severity of the primary diagnosis on the child interview, $r=0.99, p<0.01$ and the parent interview, $r=0.86, p<0.01$.

Conform standard ADIS procedures, a child receives a diagnosis in case a specified amount of criteria are met and the child or parent reports substantial interference at school, at home or in social contacts (4 or higher on a scale from 0 to 8). The combined diagnosis represents a sum of the diagnoses of the child and the parent interview.

\section{Procedure}

Children completed the SCARED-71 during regular classes, which approximately took $15 \mathrm{~min}$. They received a standardised explanation of the difficult questions. In addition, a research assistant was present in the classroom to help the children in case of difficulties. Children were selected based on the child version of the screening questionnaire, and those scoring in the top- $15 \%$ or from 2 points below to 2 points above the median were selected and asked to participate in the entire anxiety prevention study. Maximum 3 months later, the children and their parents were interviewed separately using the ADIS [47] concerning the child's anxiety disorders and other psychopathology.
Statistical analyses

Missing items $(<10 \%)$ of the screening questionnaire were replaced via regression within the standard missing value analysis provided by SPSS. Independent sample $t$ test were performed to calculate differences between mediananxious and high-anxious children regarding separate SCARED-71 subscales. Chi-square and Odds ratios were calculated to measure possible differences between the high-anxious and median-anxious children with respect to diagnostic status (yes/no), and Cohen's kappa was calculated in order to measure child-parent correspondence of diagnoses. The predictive values of the SCARED-71 subscales on their corresponding diagnosis on the ADIS were calculated by logistic regression analyses. All analyses were performed utilising Statistical Package for Social Sciences 15.0.

\section{Results}

Preliminary results

In case, either the parent or the child interview was not completed (high-anxious, $n=5$, median anxious, $n=2$ ), data of these participants were excluded from the analyses. Regarding the parent interviews, in the high-anxious group, $172(94 \%)$ mothers took part in the interview and $65(36 \%)$ fathers. A trend was found, that is, children whose father did not participate had higher self-reported anxiety scores than children whose father did participate, $t(180)=1.83$, $p=0.06$. In the median-anxious group, $76(95 \%)$ mothers took part in the interview and $17(21 \%)$ fathers, and no differences were present on child-reported anxiety scores between children whose father did participate and those children whose fathers did not participate, $t(77)=0.04$, $p>0.10$.

\section{Descriptive statistics of the SCARED-71}

The means and standard deviations of the SCARED-71 child version of high-and median-anxious children are depicted in Table 2.

Diagnoses of high- and median-anxious children

The characteristics of the participating children on the prevalence of all DSM-IV anxiety disorders, as well as the prevalence of dysthymia, depression and attention deficit hyperactivity disorder are depicted in Table 3 . There was a slight to fair agreement between children and parents regarding the presence (present/not present) of the three most frequent diagnosed anxiety disorders and the presence 
Table 2 Means and standard deviations of the screening questionnaire, and comparisons of total and subscale scores of entire high- and mediananxious group, as well as comparisons of boys' and girls' scores within the high- and median-anxious group

\begin{tabular}{|c|c|c|c|c|c|c|}
\hline & \multicolumn{3}{|c|}{ High-anxious $(n=183)$ (Mean, SD) } & \multicolumn{3}{|c|}{ Median-anxious $(n=80)$ (Mean, SD) } \\
\hline & Entire group & Girls & Boys & Entire group & Girls & Boys \\
\hline Total score (71 items) & $66.31(15.69)$ & $71.24(16.23)$ & $60.24(12.65)^{* *}$ & $25.97(3.81)$ & $28.92(2.65)$ & $23.32(2.52)^{* *}$ \\
\hline Panic disorder (13 items) & $10.18(5.08)$ & $11.05(5.36)$ & $9.10(4.52)^{* *}$ & $2.14(1.40)$ & $2.46(1.50)$ & $1.85(1.26)$ \\
\hline Generalised anxiety disorder ( 9 items) & $9.55(3.61)$ & $10.16(3.55)$ & $8.79(3.57)^{*}$ & $3.12(1.98)$ & $3.92(2.07)$ & $2.39(1.59)^{* *}$ \\
\hline Social phobia ( 9 items) & $8.43(3.41)$ & $9.20(3.38)$ & $7.49(3.21)^{* *}$ & $4.00(1.87)$ & $4.51(1.89)$ & $4.02(1.73)^{*}$ \\
\hline Separation anxiety disorder (12 items) & $10.65(3.79)$ & $11.45(4.02)$ & $9.65(3.22)^{* *}$ & $4.04(1.84)$ & $4.05(1.91)$ & $4.02(1.80)$ \\
\hline Obsessive-compulsive disorder (9 items) & $8.84(2.71)$ & $9.18(2.61)$ & $8.41(2.79)$ & $4.46(1.76)$ & $4.73(1.79)$ & $4.22(1.71)$ \\
\hline Animal phobia (3 items) & $1.95(1.87)$ & $2.43(2.03)$ & $1.35(1.45)^{* *}$ & $0.73(1.30)$ & $0.84(1.48)$ & $0.63(1.11)$ \\
\hline Blood injection injury phobia (7 items) & $6.44(2.96)$ & $6.82(2.93)$ & $5.95(2.94)^{*}$ & $3.24(1.80)$ & $3.54(1.73)$ & $2.98(1.85)$ \\
\hline Environmental sit. phobia (5 items) & $5.11(2.19)$ & $5.52(2.04)$ & $4.60(2.28)^{* *}$ & $2.31(1.56)$ & $2.73(1.66)$ & $1.93(1.37)^{*}$ \\
\hline Post-traumatic stress disorder (4 items) & $5.37(2.05)$ & $5.75(1.98)$ & $4.90(2.06)^{* *}$ & $1.94(1.72)$ & $2.14(1.92)$ & $1.76(1.53)$ \\
\hline
\end{tabular}

All means of the entire high-anxious and median-anxious groups differed significantly, at $p<0.01$

$* p<0.05, * * p<0.01$, tested two-sided

Table 3 Prevalence rates on child-report, parent-report and combined report of anxiety disorders, dysthymia, depression and attention deficit hyperactivity disorder in high-anxious and median-anxious children, and statistical comparison (Chi-square) of groups on prevalence rates of combined reports

\begin{tabular}{|c|c|c|c|c|c|c|}
\hline \multirow[t]{2}{*}{ Type of anxiety disorder } & \multicolumn{3}{|c|}{ High-anxious, $n=183$} & \multicolumn{3}{|c|}{ Median-anxious, $n=80$} \\
\hline & $\mathrm{C}$ & $\mathrm{P}$ & Com & $\mathrm{C}$ & $\mathrm{P}$ & Com \\
\hline Separation anxiety & $19(10 \%)$ & $17(9 \%)$ & $29(16 \%)^{* *}$ & $0(0 \%)$ & $1(1 \%)$ & $1(1 \%)$ \\
\hline Social phobia & $21(11 \%)$ & $22(12 \%)$ & $39(21 \%)^{* *}$ & $1(1 \%)$ & $4(5 \%)$ & $5(6 \%)$ \\
\hline Specific phobia & $62(34 \%)$ & $48(26 \%)$ & $95(52 \%)^{* *}$ & $6(8 \%)$ & $4(5 \%)$ & $9(11 \%)$ \\
\hline Panic & $3(2 \%)$ & $1(1 \%)$ & $3(2 \%)$ & $0(0 \%)$ & $1(1 \%)$ & $1(1 \%)$ \\
\hline Generalised anxiety & $17(9 \%)$ & $14(8 \%)$ & $28(15 \%)^{*}$ & $0(0 \%)$ & $4(5 \%)$ & $4(5 \%)$ \\
\hline Post-traumatic stress & $4(2 \%)$ & $1(1 \%)$ & $5(3 \%)$ & $0(0 \%)$ & $0(0 \%)$ & $0(0 \%)$ \\
\hline Obsessive compulsive & $1(1 \%)$ & $0(0 \%)$ & $1(1 \%)$ & $0(0 \%)$ & $0(0 \%)$ & $0(0 \%)$ \\
\hline Any anxiety disorder & $72(39 \%)$ & $72(39 \%)$ & $110(60 \%)^{* *}$ & $6(8 \%)$ & $12(15 \%)$ & $18(23 \%)$ \\
\hline \multicolumn{7}{|l|}{ Other disorders } \\
\hline Dysthymia/Depression & $5(3 \%)$ & $5(3 \%)$ & $8(4 \%)$ & $1(1 \%)$ & $0(0 \%)$ & $1(1 \%)$ \\
\hline Attention deficit hyperactivity disorder & $5(3 \%)$ & $11(6 \%)$ & $14(8 \%)$ & $0(0 \%)$ & $5(6 \%)$ & $5(6 \%)$ \\
\hline
\end{tabular}

$C$ Child report, $P$ parent report, $C o m$ combined report (child + parent)

$* p<0.05, * * p<0.01$, tested two-sided

of any anxiety disorder: Cohen's kappa specific phobia: 0.19; Cohen's kappa social phobia: 0.11; Cohen's kappa separation anxiety disorder: 0.30 ; Cohen's kappa any anxiety diagnosis: 0.16 .

Regarding the combined diagnoses, $60 \%$ of the highanxious children $(n=110)$ had one or more anxiety disorders, in contrast to $23 \%(n=18)$ of the median-anxious children, $\chi^{2}(1)=30.28, p<0.01$, OR $=5.0$. This was also the case when only the child interview was taken into account, $\chi^{2}(1)=26.60, p<0.01$, OR $=7.8$, or only the parent interview, $\chi^{2}(1)=14.57, p<0.01, \quad$ OR $=3.6$. High-anxious children did not have significantly more dysthymia and depression, $\chi^{2}(1)=1.59, \quad p>0.05$,
$\mathrm{OR}=3.5$, and attention deficit disorder and hyperactivity disorder, $\chi^{2}(1)=0.14, p>0.05$, OR $=1.2$.

When comparing high- and median-anxious children with one or more anxiety disorders to each other, it appeared that the severity of the primary anxiety diagnosis (range 4-8 in case of diagnosis) was significantly higher in high-anxious children $(M=4.93$, SD 0.96) than in mediananxious children $(M=4.5$, SD 0.92), $t(126)=1.77$, $p<0.05$. Additionally, in diagnosed high-anxious children, the average number of anxiety diagnoses was 2.03 (SD 1.49 , range $1-9$ ), compared to 1.11 (SD 0.32 , range $1-2$ ) in diagnosed median-anxious children, $t(117.93)=-5.692$, $p<0.001$. The most frequent diagnoses in the high-anxious 
group were specific phobia $(n=95 ; 52 \%)$, social phobia $(n=39 ; 21 \%)$, separation anxiety disorder $(n=29 ; 16 \%)$ and generalized anxiety disorder $(n=28 ; 15 \%)$. Fear of the dark is the type of specific phobia that was diagnosed the most $(27 \%$; $n=26)$, followed by spider phobia (19\%; $n=18)$, and medical phobias $(17 \% ; n=16)$.

\section{Discriminative value of SCARED-71 subscales}

In order to measure whether the anxiety disorders were predicted by their corresponding subscale of the SCARED71 , hierarchic logistic regression analyses were performed. The diagnostic status (anxiety disorder present/anxiety disorder not present) for every specific DSM-IV anxiety disorder constituted the dependent variable, whereas all subscales of the child SCARED-71 were entered as independent variables. Only those disorders with prevalence rates above 5\% and their corresponding SCARED-71 scales were taken into account (separation anxiety disorder, generalized anxiety disorder, social phobia, and specific phobia). Because of the low prevalence rates of disorders (all $<5 \%$ ) in the median-anxious group, the logistic regression analyses were only performed with high-anxious children. The results of these analyses are depicted in Table 4 .

It appeared that the disorders separation anxiety disorder, social phobia, and specific phobia were predicted by their corresponding subscale on the SCARED-71. That is, other subscales did not contribute significantly to the prediction of separation anxiety disorder, social phobia and specific phobia than their matching SCARED-71 subscales. The full model of the diagnoses separation anxiety disorder, social phobia, and specific phobia accounted, respectively, for 12,22 , and $8 \%$ of the variance. The diagnosis generalised anxiety disorder was not predicted significantly by any of the included subscales of the SCARED-71.

\section{Discussion}

This study investigated the usefulness of screening for anxiety disorders in primary school children via children's self-report of anxiety symptoms on a questionnaire. Children that had a total score in the top-15\% (high-anxious) were compared to children with a total score from 2 points below to 2 points above the median (median-anxious) with respect to their total scores and subscale scores on the screening questionnaire. Both groups received a diagnostic interview (separate child and parent interviews) to check for the presence of anxiety disorders. The predictive value of the screening questionnaire's subscales separation anxiety disorder, social phobia, specific phobia, and generalised anxiety disorder on their matching diagnosis of the interview was analysed. With respect to the tested hypotheses, it was found that: (1) high-anxious children had more often, and more severe anxiety diagnoses compared to median-anxious children; (2) high-anxious children and median-anxious children did not differ with respect to dysthymia, depression, and attention deficit hyperactivity disorder; (3) the diagnoses separation anxiety disorder, social phobia, and specific phobia were specifically predicted by their matching subscales on the screening questionnaire; (4) the diagnosis generalized anxiety disorder was not predicted by any of the included subscales the SCARED-71.

The screening instrument discriminates between children with severe anxiety difficulties and children with "normal anxiety". However, the prevalence numbers of anxiety disorders in both groups are fairly high. They exceed the general lifetime prevalence estimation of $9.9 \%$ in 16 years of age [14], as well as the prevalence rates of Muris and colleagues [36]. They reported that $27 \%$ of those children (age 8-13) labelled as high-anxious had an anxiety

Table 4 Logistic regression analyses with the SCARED subscales as independent variables and the (combined child-parent) anxiety diagnosis as the dependent variable

\begin{tabular}{|c|c|c|c|c|c|c|c|c|}
\hline & \multicolumn{2}{|c|}{$\begin{array}{l}\text { Separation anxiety } \\
\text { diagnosis }^{\mathrm{a}}\end{array}$} & \multicolumn{2}{|l|}{$\begin{array}{l}\text { Social phobia } \\
\text { diagnosis }^{b}\end{array}$} & \multicolumn{2}{|l|}{$\begin{array}{l}\text { Specific phobia } \\
\text { diagnosis }^{c}\end{array}$} & \multicolumn{2}{|c|}{$\begin{array}{l}\text { Generalised anxiety } \\
\text { diagnosis }^{\mathrm{d}}\end{array}$} \\
\hline & B (SE B) & Exp B. & B (SE B) & Exp B. & B (SE B) & Exp B. & B (SE B) & Exp B. \\
\hline Constant & $-4.47(1.00)^{* *}$ & 0.01 & $-4.14(0.89)^{* *}$ & 0.02 & $-1.89(0.67)^{* *}$ & 0.15 & $-3.32(0.90)^{* *}$ & 0.04 \\
\hline Separation anxiety disorder, screening & $0.17(0.07)^{* *}$ & 1.19 & $0.02(0.06)$ & 1.02 & $0.06(0.05)$ & 1.06 & $0.03(0.06)$ & 1.03 \\
\hline Social phobia, screening & $-0.07(0.07)$ & 0.93 & $0.30(0.07)^{* *}$ & 1.35 & $-0.04(0.05)$ & 0.96 & $0.12(0.07)$ & 1.13 \\
\hline Sum specific phobia, screening & $0.06(0.05)$ & 1.06 & $-0.01(0.04)$ & 0.99 & $0.10(0.04)^{* *}$ & 1.10 & $0.00(0.05)$ & 1.00 \\
\hline Generalised anxiety disorder, screening & $0.05(0.07)$ & 1.06 & $0.00(0.07)$ & 1.00 & $-0.01(0.05)$ & 0.99 & $0.03(0.07)$ & 1.03 \\
\hline
\end{tabular}

${ }^{a}$ Separation anxiety disorder, $R^{2}=0.12$. (Nagelkerke). Model $\chi^{2}(13.21)=p<0.05$

b Social phobia, $R^{2}=0.22$. (Nagelkerke). Model $\chi^{2}(28.57)=p<0.01$

${ }^{c}$ Specific phobia, $R^{2}=0.08$. (Nagelkerke). Model $\chi^{2}(11.24)=p<0.05$

${ }^{\mathrm{d}}$ Generalised anxiety disorder, $R^{2}=0.06$. (Nagelkerke). Model $\chi^{2}(5.93)$ ' $n s$

$* p<0.05, * * p<0.01$, tested two-sided 
disorder. Two methodological explanations can be offered for the high prevalence rates of anxiety disorders in both groups. First, we used a combined parent-child diagnosis, whereas most studies [e.g. 36] on prevalence rates use either parent or child reports. Because of the low correspondence between the children and their parents with regard to the type of anxiety disorder, the combination of the parent and child scores is likely to yield higher prevalences of anxiety diagnoses. Second, we compared highanxious children to median-anxious children, whereas lowanxious children were excluded from participation. Despite these methodological explanations, prevalence rates remain high in both groups, especially in the median-anxious group. In her meta-analysis on birth cohort change in anxiety, Twenge reported that children $(N=12,056$, age range: 9-17) increased one standard deviation on selfreported anxiety between 1952 and 1993. In fact, children considered as normal anxious in the 1980s, scored higher on self-reported anxiety compared to child psychiatric patients in the 1950s [54]. Anxiety has thus been found to increase over time. However, it would be too premature to draw conclusions on whether the methodological or timerelated aspects caused the fairly high prevalence rates of anxiety disorders in the current study.

Even though studies that selected children via clinical settings showed high comorbidity between anxiety and other mental health problems [51], in this study high-anxious and median-anxious children did not differ with respect to the number of the disorders dysthymia, depression, and attention deficit hyperactivity disorder. The low comorbidity of anxiety disorders with dysthymia, depression, and attention deficit hyperactivity disorder is likely to result from two characteristics of our sample, being a community sample and a young sample, aged 8-12. As mentioned before, anxiety disorders are chronic if untreated and, as a consequence, can lead to other mental health disorders $[3,9$, $31,43,51,56]$.

The odds ratio reflecting higher relative risk of highanxious children having an anxiety disorder compared to median-anxious children $(\mathrm{OR}=5.0$, combined parentchild report) increased in case the diagnosis was based only on the child interview, OR 7.8, and decreased when based only on the parent interview, OR 3.6. Multiple investigators pointed out that child's self-report scores on internalising symptoms, like anxiety and depression measures, exceed parent reports [19, 25, 55]. Children are thought to have better perceptions of their anxiety than parents. Horowitz, for example, noted that parents are less likely to be aware of internalising problems compared to externalising problems [27]. This is supported by the low referral in the high-anxious groups, which is, at this age, usually instigated by the parents or school. However, even though correspondence between the parent and the child on the interview was found to be low, parents did not report less anxiety disorders compared to the children. Another explanation that could be offered to clarify the differences in odds ratio's is that the children were selected based on the child version of the screening questionnaire.

The most frequent diagnoses in the high-anxious group were specific phobia $(52 \%)$, social phobia $(21 \%)$, separation anxiety disorder $(16 \%)$ and generalised anxiety disorder $(15 \%)$. We employed logistic regression analyses to test the expectation that the diagnoses specific phobia, social phobia, separation anxiety disorder, and generalised anxiety disorder were specifically predicted by their corresponding subscale of the screening instrument in the high-anxious group. The expectation was partly supported. It appeared that the three of the most prevalent disorders separation anxiety disorder, social phobia and specific phobia were only predicted by their corresponding subscales on the screening questionnaire. The finding of the specific correspondence between the social phobia and separation anxiety disorder subscales of the screening questionnaire with their matching diagnoses is in accord with the study of Muris and colleagues using clinically anxious children [34]. However, an earlier study of Muris with elementary school children [36] found that the diagnosis social phobia was predicted by the subscale separation anxiety disorder. Possibly, the elaboration of the social phobia subscale with 5 items, lead to a better predictive value of that SCARED-71 subscale.

The diagnosis generalised anxiety disorder was not predicted significantly by any of the included subscales of the SCARED-71. Perhaps children of this age have difficulty understanding the concept of worrying (e.g. "I worry about the future"), or items on worrying are so general that they apply to some extent to all children with anxiety disorders. Generalised anxiety disorder generally has higher comorbidity rates than other anxiety disorder and is highly comorbid with major depression [15]. Note that "depressive symptoms" does not constitute a subscale on the SCARED-71 and was thus not included in the prediction of generalised anxiety disorder. According to Pine and Klein [45], the high comorbidity of generalised anxiety disorder with other disorders and depression in children "raises questions about whether the diagnosis identifies a unique syndrome as opposed to a complication of other associated disorders". More research is clearly necessary on how to detect generalised anxiety disorder in children aged $8-12$.

Limitations

The pre-selection of groups in high- and median-anxious was based on child report on an anxiety symptoms 
questionnaire. Although it is generally assumed that children are the most reliable reporters of internalising symptoms, children who underestimate their anxiety have not been selected in the high-risk group. Further studies are needed to investigate to what extent combining child report with that of knowledgeable others (e.g. parents, teachers, siblings, friends) could improve the selection of children suffering from anxiety disorders.

Approximately half of the children that were approached for the screening completed the screening questionnaire and approximately half of those identified as high- or median-anxious participated in the diagnostic interview. Results of this study that are based on this sample should, therefore, be generalised to the entire population with care. The possibility that motivation or elevated anxiety levels are related to participation rate should be considered. However, comparable and even lower participation rates are found in other anxiety prevention studies. For example, in an indicated prevention trial of Rapee and colleagues, $29.4 \%$ of the distributed screening packets were returned and $63.2 \%$ of those identified as at-risk for anxiety disorders (based on an elevated anxiety score) participated in further testing [46]. Additionally, in an early intervention trial of Dadds and colleagues [17], $41 \%$ of those identified as at-risk for anxiety disorders participated in further testing. The low participation rates should, therefore, be considered as a reflection of difficulties of programs aimed at prevention rather than as a limitation of the current study.

The cross-sectional nature of the study concerns another limitation. Even though the main aim was to investigate the usefulness of screening methods in anxiety, longitudinal studies are preferred in order to properly examine time related developments of prevalence rates and the predictive value of the screening questionnaire for the development of anxiety disorders.

\section{Conclusion}

Anxiety disorders are highly prevalent in children, and have negative effects on children's quality of life. In case anxiety disorders are not managed in an early stage, the anxious individual is less likely to seek professional help, whereas he or she is more likely to develop more severe anxiety disorders, or other disorders. It is, therefore, of importance to stimulate the identification of dysfunctional anxiety in an early stage. A screening instrument, such as the SCARED-71 can enhance this process. Results from this study point to the usefulness of screening procedure, as children with high total scores (high-anxious) had more and more severe anxiety disorders than children with total scores from 2 points below to 2 points above the median (median-anxious). In addition, separation anxiety disorder, social phobia, and specific phobia, all diagnoses known to be prevalent and debilitating, were predicted by their corresponding subscales of the SCARED-71. Future studies should investigate if high-anxious children are not only at risk for current anxiety disorders, but also for the development of future anxiety disorders and for a chronic course of anxiety disorders. In longitudinal studies, the effect of the employment of lower cut-off scores could be examined as well, in order to establish to what extend these children are at risk for developing anxiety disorders in the future.

Acknowledgments The authors thank the participating children and their families. This study was supported by: Zorg onderzoek Nederland-MW (ZonMW), grant number: 22000138 to the second author.

Open Access This article is distributed under the terms of the Creative Commons Attribution Noncommercial License which permits any noncommercial use, distribution, and reproduction in any medium, provided the original author(s) and source are credited.

\section{References}

1. American Psychiatric Association (1994) Diagnostic and statistical manual of mental disorders, 4th edn. American Psychiatric Association, Washington DC

2. Anderson JC, Williams S, McGee R, Silva PA (1987) DSM-III disorders in preadolescent children. Arch Gen Psychiatry 44:6976

3. Barlow D, DiNardo P, Vermilyea B, Blanchard E (1986) Comorbidity and depression among anxiety disorders: issues in diagnosis and classification. J Nerv Ment Dis 174:63-72

4. Birmaher B, Brent D, Chiapetta L, Bridge J, Monga S, Baugher M (1999) Psychometric properties of the screen for child anxiety related emotional disorders (SCARED): a replication study. J Am Acad Child Adolesc Psychiatry 38:1230-1236

5. Bittner A, Egger HL, Erkanli A, Costello EJ, Foley DL, Angold A (2007) What do childhood anxiety disorders predict? J Child Psychol Psychiatry 48:1174-1180

6. Bodden DHM, Bögels SM, Muris P (submitted) The diagnostic utility of the screen for child anxiety related emotional disorders71 (SCARED-71)

7. Bodden DHM, Dirksen CD, Bögels SM (2007) Societal burden of clinically anxious youth referred for treatment: a cost-of-illness study. J Abnorm Child Psychol 36:487-497

8. Bögels SM, Van Melick M (2004) The relationship between child-report, parent self-report, and partner report of perceived parental rearing behaviors and attitudes in children and parents. Personality Individ Differ 37:1583-1596

9. Brady E, Kendall PC (1992) Comorbidity of anxiety and depression in children and adolescents. Psychol Bull 111:244255

10. Castellanos D, Hunter T (1999) Anxiety disorders in children and adolescents. South Med J 92:946-953

11. Christiana JM, Gilman SE, Guardino M, Mickelson K, Morselli PL, Olfson M et al (2000) Duration between onset and time of obtaining initial treatment among people with anxiety and mood disorders: an international survey of members of mental health patient advocate groups. Psychol Med 30:693-703

12. Cohen P, Cohen J, Kasen S, Velez CN, Hartmark C, Johnson J et al (1993) An epidemiological study of disorders in late 
childhood and adolescence-I: age- and gender-specific prevalence. J Child Psychol Psychiatry 34:851-866

13. Costello EJ, Egger H, Angold A (2005) The developmental epidemiology of anxiety disorders: phenomenology, prevalence, and comorbidity. Child Adolesc Psychiatr Clin N Am 14:631-648

14. Costello EJ, Mustillo S, Erkanli A, Keeler G, Angold A (2003) Prevalence and development of psychiatric disorders in childhood and adolescence. Arch Gen Psychiatry 60:837-844

15. Costello E, Pine DS, Hammen C, March JS, Plotsky PM, Weissman MM et al (2002) Development and natural history of mood disorders. Biol Psychiatry 52:529-542

16. Craske MG (1997) Fear and anxiety in children and adolescents. Bull Menninger Clin 61:A4-A36

17. Dadds MR, Spence SH, Holland DE, Laurens KR, Mullins M, Barrett PM (1999) Early intervention and prevention of anxiety disorders in children: results at 2-year follow-up. J Consult Clin Psychol 67:145-150

18. Dweck C, Wortman C (1982) Learned helplessness, anxiety, and achievement. In: Krohne H, Laux L (eds) Achievement, stress, and anxiety. Hemisphere, New York

19. Edelbrock C, Costello AJ, Dulcan MK, Conover NC, Kala R (1986) Parent-child agreement on child psychiatric symptoms assessed via structured interview. J Child Psychol Psychiatry 27:181-190

20. Essau CA, Barrett P (2001) Developmental issues in the assessment of anxiety. In: Essau CA, Petermann F (eds) Anxiety disorders in children and adolescents: epidemiology, risk factors, and treatment. Harwood Academic Publishers, London

21. Essau CA, Conradt J, Petermann F (2000) Frequency, comorbidity, and psychosocial impairment of anxiety disorders in adolescents. J Anxiety Disord 14:263-279

22. Feehan M, McGee R, Williams SM (1993) Mental health disorders from age 15 to age 18 years. J Am Acad Child Adolesc Psychiatry 32:1118-1126

23. Giaconia RM, Renherz HZ, Silverman AB, Pakiz B, Frost AK, Cohen EL (1994) Ages of onset of psychiatric disorders in a community population of older adolescents. J Am Acad Child Adolesc Psychiatry 33:706-717

24. Hien D, Matzner FJ, First MB, Spitzer RL, Gibbon M, Williams JBW (1998) Structured clinical interview for DSM-IV-child edition (version 1.0). Columbia University, New York

25. Hodges K, Gordon Y, Lennon MP (1990) Parent-child agreement on symptoms assessed via a clinical research interview for children: the child assessment schedule (CAS). J Child Psychol Psychiatry 31:427-436

26. Hoehn-Saric RE, Hazlett RL, McLeod DR (1993) Generalized anxiety disorder with early and late onset of anxiety symptoms. Compr Psychiatry 34:291-298

27. Horowitz SM, Leaf PJ, Leventhal JM (1998) Identification of psychosocial problems in pediatric primary care: do family attitudes make a difference? Arch Pediatr Adolesc Med 152:367-371

28. Keller M, Lavori P, Wunder J, Beardslee W, Schwartz C, Roth J (1992) Chronic course of anxiety disorders in children and adolescents. J Am Acad Child Adolesc Psychiatry 31:595-599

29. Kessler RC, Berglund P, Demler O, Jin R, Merikangas KR, Walters EE (2005) Lifetime prevalence and age-of-onset distributions of DSM-IV disorders in the national comorbidity survey replication. Arch Gen Psychiatry 62:593-602

30. Kovacs M (1996) Presentation and course of major depressive disorders during childhood and later years of the life span. J Am Acad Child Adolesc Psychiatry 35:705-715

31. Last CG, Strauss CC, Francis G (1987) Comorbidity among childhood anxiety disorders. J Nerv Ment Dis 175:726-730

32. Lipsitz JD, Martin LY, Manuzza S, Chapman TF, Liebowitz MR, Klein DF et al (1994) Childhood separation anxiety disorder in patients with adult anxiety disorders. Am J Psychiatry 151:927929

33. McGee R, Feehan M, Williams S, Partridge F, Silva PA, Kelly J (1990) DSM-III disorders in a large sample of adolescents. J Am Acad Child Adolesc Psychiatry 29:611-619

34. Muris P, Dreesen L, Bögels SM, Weckx M, Van Melick M (2004) A questionnaire for screening a broad range of DSMdefined anxiety disorder symptoms in clinically referred children and adolescents. J Child Psychol Psychiatry 45:813-820

35. Muris P, Merkelbach H, Gadet B, Mouleart V, Tierney S (1999) Sensitivity for treatment effects of the screen for child anxiety related emotional disorders. J Psychopathol Behav Assess 21:323-335

36. Muris P, Merkelbach H, Kindt M, Bögels SM, Dreesen L, Dorp C et al (2001) The utility of screen for child anxiety related emotional disorders (SCARED) as a tool for identifying children at high risk for prevalent anxiety disorders. Anxiety Stress Coping 14:265-283

37. Muris P, Merkelbach H, Schmidt H, Mayer B (1999) The revised version of the Screen for child anxiety related emotional disorders (SCARED-R): factor structure in normal children. Personality Individ Differ 26:99-112

38. Muris P, Merkelbach H, van Brakel A, Mayer B (1999) The screen for child anxiety related emotional disorders (SCARED): further evidence for its reliability and validity. Anxiety Stress Coping 12:411-425

39. Muris P, Schmidt H, Merckelbach H (2000) Correlations among two self-report questionnaires for measuring DSM-defined anxiety disorder symptoms in children: the screen for child anxiety related emotional disorders and the spence children's anxiety scale. Personality Individ Differ 28:333-346

40. Muris P, Steernema $P$ (2001) The revised version of the screen for child anxiety related emotional disorders (SCARED-R): first evidence for its reliability and validity in a clinical sample. Br J Clin Psychol 40:35-44

41. Newman DL, Moffitt TE, Caspi A, Magdol L, Silva PA, Stanton WR (1996) Psychiatric disorder in a birth cohort of young adults: prevalence, comorbidity, clinical significance, and new cases from ages 11 to 21. J Consult Clin Psychol 64:552-562

42. Ollendick TH, King NJ (1998) Empirically supported treatments for children with phobic and anxiety disorders: current status. J Clin Child Psychol 27:156-167

43. Otto M, Pollock M, Rosenbaum JF, Sachs GS, Asher RH (1994) Childhood history of anxiety in adults with panic disorder: association with anxiety sensitivity and comorbidity. Harv Rev Psychiatry 1:288-293

44. Pine DS, Cohen P, Gurley D, Brook J, Ma Y (1998) The risk for early-adulthood anxiety and depressive disorders in adolescents with anxiety and depressive disorders. Arch Gen Psychiatry 55:56-64

45. Pine DS, Klein RG (2008) Anxiety disorders. In: Rutter M, Bishop D, Pine D, Scott S, Stevenson J, Taylor E, Thapar A (eds) Rutter's child and adolescent psychiatry. Blackwell, Oxford

46. Rapee RM, Kennedy S, Ingram M, Edwards S, Sweeney L (2005) Prevention and early intervention of anxiety disorders in inhibited preschool children. J Consult Clin Psychol 73:488497

47. Siebelink BM, Treffers PDA (2001) Nederlandse bewerking van het anxiety disorder interview schedule for DSM-IV: child version van W. K. Silverman en A.M Albana. Swets \& Zeitlinger, Lisse/Amsterdam

48. Silverman WK, Saavedra LM, Pina AA (2001) Test-retest reliability of anxiety symptoms and diagnoses with anxiety disorders interview schedule for DSM-IV child and parent version. J Am Acad Child Adolesc Psychiatry 40:937-944 
49. Slobbe LCJ, Kommer GJ, Smit JM, Groen J, Meerding WJ, Polder JJ (2006) Kosten van ziekten in Nederland 2003; zorg voor euro's 1. RIVM-rapport nr. 270751010. RIVM, Bilthoven

50. Spence SH (1998) A measure of anxiety symptoms among children. Behav Res Ther 36:545-566

51. Stauss CC, Last CG, Hersen M, Kazdin AE (1988) Association between anxiety and depression in children and adolescents with anxiety disorders. J Abnorm Child Psychol 16:57-68

52. Strauss CC, Lease C, Kazdin A, Dulcan M, Last C (1989) Multimethod assessment of social competence of children with anxiety disorders. J Clin Child Psychol 18:184-189

53. Turner SM, Beidel DC, Costello A (1987) Psychopathology in the offspring of anxiety disorders patients. J Consult Clin Psychol 55:229-235
54. Twenge JM (2000) The age of anxiety? Birth cohort change in anxiety and neuroticism, 1952-1993. J Pers Soc Psychol 79:1007-1021

55. Verhulst FC, Althaus M, Berden GF (1987) The child assessment schedule: parent-child agreement and validity measures. J Child Psychol Psychiatry 28:455-466

56. Wittchen HU, Essau CA (1994) Epidemiology of anxiety disorders. In: Wilner PJ (ed) Psychiatry. JB Lippincott Company, Philadelphia

57. Wren FJMB, Bridge JA, Birmaher B (2004) Screening for childhood anxiety symptoms in primary care: integrating child and parent reports. J Am Acad Child Adolesc Psychiatry 43:1364-1371 